\title{
Sciendo
}

DOI 10.2478/afepuc-2020-0003

(C) Acta Facultatis Educationis Physicae Universitatis Comenianae 2020, 60(1): 32-43

\section{EFFECT OF SPRINT TRAINING EXERCISE, SHUTTLE RUN AND PREVENTION ON BASE SOFTBALL RUNNING SPEED AMONG HIGH SCHOOL STUDENTS}

\author{
Amirudin Fathoni ${ }^{1}$, Hari Amirullah Rachman ${ }^{2}$ \\ ${ }^{1}$ Sports Science of Postgraduates Program, Universitas Negeri Yogyakarta, INDONESIA \\ ${ }^{2}$ Sport Science of Faculty, Universitas Negeri Yogyakarta, INDONESIA
}

\begin{abstract}
Summary. This study aims to determine the differences and to achieve better effect in the sprint training, shuttle run and agility on base of running speed of athletes softball. This study uses an experimental method with a $2 \times 2$ factorial design. Participants in this research were 42 male athletes (mean age $=16.88 ; \mathrm{SD}=1.31$ ), Indonesian high school students. The instruments of this study were the base running test and reactive agility testing protocols. Analysis of the data is analysis of variance (ANOVA) of two pathways at a significant level $\alpha=0.05$. The results of the study are as follows: exercise sprint training give better effect to the results of base running extracurricular softball, as evidenced by the value of $p=0.036<0.05$. Participants who have high agility level give a better effect than participants who have low agility level on the results of softball extracurricular base running, as evidenced by the value of $p=0,000<0.05$. There is no interaction between the training model and agility on the results of softball extracurricular base running, which is evident from the value of $p=$ $0.634>0.05$. This research contributes to the field of softball sports, especially in creating an appropriate training program to increase the speed of base running in male students by using sprint training so that results are more effective.
\end{abstract}

Key words: agility, athlete, exercise, run, softball, speed

\section{Introduction}

Softball game sport is one of the sports that is included in the physical education curriculum, this game requires technical mastery and a long enough game time, so this game is included in extracurricular activities (Burhaein 2017b; Srinivasan, Pescatello \& Bhat 2014). The existence of softball extracurriculars in certain schools, the sports teacher or extracurricular coaches must be able to master softball material, basic techniques and rules of 
the game, so that they do not experience difficulties in carrying out these extracurricular activities. Physical conditions are the basic needs of every sport. In achieving an achievement, physical condition is the initial provision and as a basic basis for participating in sports training. In addition, physical conditions are the foundation and barometer of achievement and the ability of biomotor or fitness components required by an athlete (Burhaein 2017b; Srinivasan, Pescatello \& Bhat 2014). Exercise to improve physical conditions can develop and improve the physical condition of athletes. Techniques, tactics and psychics can be well developed if they have good quality physical condition. Thus, athletes and sportsmen have to have a physical condition that is good for excellent physical condition to help them reach the achievement of the maximum. The elements of physical condition namely heart and lung endurance, speed, strength, agility, flexibility, explosive power, coordination, balance, accuracy and speed of reaction (Burhaein 2017b; Srinivasan, Pescatello \& Bhat 2014). Softball requires an element of physical condition to support the athlete's achievement. If analyzed from the movements of running between bases (base running) in softball sports, movements from the legs, legs, hips and arms are needed as a balance. An athlete's physical condition or initial abilities can be improved through a programmed training process so that the desired achievements can be achieved (Dosil, Cremades \& Rivera 2014; Hakim, Ambardini, Nugroho \& Burhaein 2018). The physical condition element is very possible to support an athlete's skill level to run to each base in softball games. One of the basic techniques in softball games, which is often overlooked in its functions and basic techniques so that many do not match what is expected is running speed. Training by applying good and appropriate training methods is an effort to increase the ability in running speed base running must be done. To make it easy for players to learn without leaving the basic technique of running, it is necessary to design an exercise method that suits the student's character. We recommend that you first explore the factors that affect the speed of running base running, so that the training methods to be applied can be designed properly. Apart from the main elements or physical components that must be considered in training are the principles of training so that the exercise can be done properly and appropriately.

Agility is a component of motor freshness that is needed in all activities that require speed of changes in body position (Purnomo, Tomoliyus \& Burhaein 2019; Young \& Willey 2010). Agility is part of movement skills and sports techniques, especially movements that require continued movement coordination. Agility is needed for high adaptability to changes in the situation in the game (Purnomo, Tomoliyus \& Burhaein 2019; Young \& Willey 2010). Urgently needed agility to change a different position in high speed with good 
coordination and balance, means that the agility is quite good. This is very closely related to softball as an infield or outfield player. High agility is a capital in addition to speed because the conditions during the game is very possible once an athlete takes a short decision, it aims to outwit your opponent or get a value.

Sprint training is an exercise that is done with intensity or full speed interspersed with rest periods during each training session and completed in a short time, and done repeatedly to the maximum on a flat surface and resilient like grass, mat or ground (Phytanza, Burhaein, Sukoco \& Ghautama 2018; Srinivasan et al. 2014). One form of exercise to improve agility is shuttle run. Shuttle run exercises are done as fast as possible starting from one point to another by covering a certain distance. Motion elements in shuttle run exercises are running by changing the direction and position of the body, speed, balance are components of agile motion so that this exercise can be used to increase agility. The advantage of shuttle run training is that this exercise is oriented on footwork, speed, which gets a lot of portion in this exercise. Agility is the ability for a person to run fast by changing his direction. If a base runner has good speed and agility, it will be easy to get points in softball matches.

Jumping, running, and changing direction speed are specific variables that must be treated separately (Nimphius, McGuigan \& Newton 2010). The three forms of exercise are both having a good influence in increasing running speed, so that it will affect the running speed of base running. But on the other hand, base running speed is not only influenced by the form of exercise applied. Individual factors (athletes) are crucial to the mastery of the skills learned. Several studies report that improvement in running skills or agility as a result of increased strength in lower limb muscles (Nimphius, McGuigan \& Newton 2010). It needs to be studied and examined more thoroughly both in theory and practice through experimental research, to find out which form of exercise has better impact on sprint training, shuttle run and agility and their influence on the speed of running base running.

\section{Methods}

Participants in this research were 42 male athletes (mean age $=16.88 ; \mathrm{SD}=1.31$ ), Indonesian highschool students. This research is an experimental research, using two groups which will receive different treatment (Toomela 2010). The method used in this study is an experimental research method using a 2 x 2 feature design (Toomela 2010). The procedure of conducting research followed the flow of the implementation of experimental research in the form of pretest, treatment, and posttest. Sprint training methods with high intensity and full speed interspersed with breaks during each training session. And the shuttle run training 
method runs as fast as possible starting from one point to another over a certain distance by changing the direction and position of the body, speed, balance. Furthermore, the experimental research method using this 2 × 2 factorial design, can be described in tabular form on the next page.

Table 1

Research Design of Experiment

\begin{tabular}{|c|c|c|}
\hline \multirow{2}{*}{$\begin{array}{c}\text { Attributive Variable (B) } \\
\text { Manipulative Variable (A) }\end{array}$} & \multicolumn{2}{|c|}{ Method of Exercise } \\
\cline { 2 - 3 } & Sprint Training (A1) & Shuttle Run (A2) \\
\hline High Agility (B1) & A1B1 & A2B1 \\
\hline Low Agility (B2) & A1B2 & A2B2 \\
\hline
\end{tabular}

Source: Analysis data research (2020)

Information:

A1B1: Group with high agility treated by using a training methods sprint training.

A2B1 : Group with high agility treated by using a training method shuttle run.

A1B2 : Group with low agility treated by using a training methods sprint training.

A2B2: Group with low agility treated by using a training method shuttle run.

The instruments of this study were the base running test and reactive agility testing protocols. The base running test uses instructions from the softball choice sports book Parno's (Parno, 1992) and the journal Sintara's (Sintara \& Sonchan 2015). Reactive agility testing protocols. This test is done by giving the opportunity to run according to the instructions of the agility test by running as fast as possible, when turning the stopwatch starts to run until the final turn (Young \& Willey 2010).

Data collection techniques, prior to the experiment, first male students participating in softball extracurricular consisting of 42 people were given agility tests Reactive agility testing protocols to measure the level of agility of each student. After the agility data were collected, the first step in the analysis was to identify the upper and lower groups using the overall score. The sample used was $27 \%$ top score and $27 \%$ bottom score. Two steps to analyze included: (1) organizing agility tests in determining high scores and low scores, (2) determining $27 \%$ high scores and $27 \%$ low scores by placing them in the same group. This group is called the upper group and lower group, thus $27 \%$ upper group and $27 \%$ lower group are considered the best for maximizing the differences between the two groups (Toomela 2010). After knowing the level of student agility, then 42 students participating in softball extracurricular activities were ranked first by sorting from the highest level to the lowest level based on the overall student agility results. Furthermore, the sample will consisted of $27 \%$ of students who had high agility and $27 \%$ of students who had low agility. Then each group was divided into 2 groups again so that it consisted of 4 groups. Based on 
this, the sample used consisted of 7 people who had high agility and 7 people who had low agility were trained using the sprint training method, 7 people who had high agility and 7 people who had low agility were trained using the shuttle run method. While the rest of students who had middle motivation were not included.

Data analysis technique used for hypothesis testing was the analysis of variance (ANOVA) two paths. Hypothesis testing was done with a significance level $\alpha=0.05$. Next, to compare the average pair of treatments the Tukey test was used (Sudjana 2002). Considering that the research data analysis was carried out using ANOVA, before testing, it was necessary to conduct a data reliability test and test the analysis requirements which include the normality test and homogeneous variant bag test (Sugiyono 2014).

\section{Results \& Discussion}

Discussion of the results of this study provides further thought and interpretation regarding the results of data analysis that have been stated previously. Based on hypothesis testing, the following discussion was produced:

\section{There were differences between the softball extracurricular groups that were trained} using the sprint training exercise and the groups that were trained using the shuttle run exercises.

Table 2

Result of ANOVA experiment group are trained using the sprint training exercise and the groups that are trained using the shuttle run exercises

\begin{tabular}{|c|c|c|c|c|}
\hline $\begin{array}{c}\text { Type III Sum } \\
\text { of Squares }\end{array}$ & $\boldsymbol{d f}$ & Mean Square & $\boldsymbol{F}$ & $\boldsymbol{p}$ \\
\hline 6.070 & 1 & 6.070 & 5.068 & 0.036 \\
\hline
\end{tabular}

Source: Analysis data research (2020)

Based on the results of the analysis of research data, it was stated that the first hypothesis was confirmed that there was a difference in the influence of the softball extracurricular groups that were trained using sprint training with the groups trained with shuttle run exercises. This could be seen from the results of signification $p=0.036<0.05$ so this result can be interpreted that the sprint training method can increase the speed of base running. According to Parno (Parno 1992), sprint training is an effective exercise for developing pure speed, reaction speed in sprinter, running skills and coordination of sprinting and developing maximum speed and leg muscle strength. To increase the speed, sprint 
training program in research is done at a distance of 30 meters with the intensity of stimulation between sub-maximal and super-maximal, simultaneously stimulated between 5 20 seconds so that the total volume was between $5-15$ times the competition distance. The frequency of stimulation was repeated $5-6$ times per exercise and $2-4$ times a week during the competitive phase.

Short sprints often occur during softball games. Running straight is the action most often performed on athletes whose shots are less than the maximum, both for hitter and runner on each base. Straight line running speed (both acceleration and maximum running speed), certain dexterity skills and repetitive running skills are shown to distinguish groups from different levels of performance. Professional players become faster over time, which shows that running speed is becoming increasingly important in softball base running. Some softball-related training has had a positive effect on running ability, leading to the assumption that all types of training can be carried out successfully. The aim is to be included in the softball training program. Although the principle of specificity clearly exists, some questions remain regarding optimal training methods in the larger context of team sports arrangements to consider time efficiency.

Training sprint training was recently conducted on elite softball players have shown a positive effect after the training sprint only once a week (Young \& Willey 2010). Exercises that are done repeatedly with an intensity according to the exercise program will have a good effect on both athletes, this will be better if the exercise is done often repeated with repetitions and sets that are increasing. Repeated running is mainly classified as anaerobic exercise, but the contribution of aerobic metabolism increases with repetition. Sets and repetition must be related to distance and intensity when designing a sprint conditioning program. The importance of peak speeds increases when the sprint starts from jogging or is not stationary. It is also important to remember that $80-90 \%$ of the maximum sprint speed is reached after 2 - 3 seconds. Sprints on base running are very important because runners who pass will create value for their team. Other studies have shown positive results when training sprint have been done at the beginning of the season or early preseason games. The ability to repeat sprints is the ability to do repeated sprints with short recovery intervals (Young et al. 2015).

Based on expert opinion and the results of the above research obtained in the field, it can be concluded that the sprint training method has a better influence in running base running on softball extracurricular male students. Besides when training has a short recovery, this is also because sprint training provides a more real picture during softball matches, because not all hitters create good shots. 


\section{There was a difference in the effect of high agility with low agility on the speed of softball extracurricular base running.}

Table 3

Result of ANOVA high agility with low agility on the speed of softball extracurricular base running

\begin{tabular}{|c|c|c|c|c|}
\hline Type III Sum of Squares & $\boldsymbol{d} f$ & Mean Square & $\boldsymbol{F}$ & $\boldsymbol{p}$ \\
\hline 23.108 & 1 & 23.108 & 19.294 & 0.000 \\
\hline
\end{tabular}

Source: Analysis data research (2020)

Based on the ANOVA test results in the above table, it was shown that the significance value of $0.036 \leq 0.05$, then $\mathrm{HO}$ is rejected and $\mathrm{Ha}$ is accepted, so it can be said there is a difference between the training methods between sprint training and shuttle run to base running speed on extracurricular participants softball. Thus the first hypothesis stated that the sprint training method is better than the shuttle run method.

Most agility tests in softball are designed to evaluate the physical quality of the players, without cognitive challenges (choice reactions). The softball field in the form of a square crossing with a $90^{\circ}$ turn, in a running strategy back and forth, sideways, and back with maximum intensity is the usual exercise used. Several studies have reported that professional players have better dexterity skills compared to players with lower standards (Francova et al. 2013; Pramantik \& Burhaein 2019). Means that action and decision making are important elements in developing the ability to express speed and agility in match conditions.

Expert opinion also shows the importance of high agility in sports games. They emphasize the fact that the speed of movement is only one component of complex motor abilities called agility (Francova et al. 2013). Agility often includes running in a straight line or intentional change of direction quickly. The basic definition of agility is too simple, because it is now considered to be far more complex not only involving speed, but also balance, coordination, and the ability to react to changes in the environment, so high agility is needed to meet all of these. High agility as rapid whole body movement with changes in speed or direction in response to stimulus, based on the conception that agility has a relationship with physical and cognitive components (Wallace, Kernozek \& Bothwell 2007). Agility context not only consist of changes in the ability of the direction but also the perception and decision-making. In much the same way as expression of speed, agility in the context of team sports is multifactorial. This implies that the development of agility in sports games is very important for optimizing the preparation of sports players. 
From some experts it can be concluded that high agility is needed in sports by involving speed, coordination, balance and direction changes quickly. High agility is needed for softball players, especially base runners who have to make decisions quickly to get points. This must be complex for all softball players, ranging from speed to high agility.

\section{There was no interaction between the methods of sprint training, shuttle run and} agility to the speed of running base running in male students extracurricular softball.

Table 4

Result of ANOVA interaction of training methods and agility towards the results of base running

\begin{tabular}{|c|l|c|c|c|}
\hline Type III Sum of Squares & $\boldsymbol{d f}$ & Mean Square & $\boldsymbol{F}$ & $\boldsymbol{p}$ \\
\hline 0,280 & 1 & 0,280 & 0,233 & 0.634 \\
\hline
\end{tabular}

Source: Analysis data research (2020)

Based on the ANOVA test analysis results above, it can be seen that the value of $p=$ $0.634 \geq 0.05$, then $\mathrm{HO}$ is accepted and Ha is rejected. So that it can be said that there is no interaction between the two sprint training exercises, shuttle run and agility on the results of the running students' softball extracurricular students. Thus the third hypothesis stated that there is no interaction between the two sprint training exercises, shuttle run and agility on the results of the softball extracurricular base running. The following is a graphic image that shows the absence of interaction between the two sprint training exercises, shuttle run and agility towards the results of the softball extracurricular base running.

Based on the analysis of research data, it was stated that the third hypothesis showed no significant difference between the interactions of the two sprint and shuttle training exercises on running speed based on the extracurricular softball of male students.

The results of the first hypothesis indicate that the sprint training method gives a better effect than the shuttle run training method to give effect to all base run speeds running extracurricular softball. While the second hypothesis shows that students with all the agility of the high category are better than students with the lower category of running speed based on extracurricular softball.

The third hypothesis showed no significant difference between the interaction of practice sprint training, shuttle run and agility on to the velocity base running extracurricular softball. This can be seen in the result $\mathrm{p}=0.634>0.05$ so that from these results it can be stated that there is no interaction between the training method and the agility of the softball extracurricular base running ability. Exercise sprint training aims to improve the 
speed of running, exercise programs sprint training in this study conducted with a distance of 30 meters, with the stimulus intensity between the maximum and super maximum sub., simultaneously stimulated between $5-20$ seconds so that the total volume is between $5-15$ times the competition distance. The frequency of stimulation is repeated $5-6$ times per exercise and $2-4$ times a week during the competitive phase.

The effect of sprint training, on softball players, can benefit more by conducting sprint training that is similar to the developmental model used in strength training and by worldleading athletic practitioners (Dosil et al. 2014). So the sprint training exercises use training programs that each session places an increasing burden with rest periods between reps and sets. The impact of sprint training exercises gives better results because it matches the game strategy. Many extracurricular softball players whose shots have not been maximized, this can be tricked by running with all their strength to immediately reach the base in front of him.

Shuttle run or run back and forth is one way to improve the speed and agility (Wirat Sonchan \& Pratoom Moungmee 2017). Through this exercise, anaerobic fitness will be better. The shuttle run training is oriented to footwork speed and is easier to remember so that the athlete can concentrate fully on running speed and if done continuously the athlete will be accustomed to sharp turning angles in 1800 (Deane, Chow, Tillman \& Fournier 2005). Thus, through the test shuttle run agility of feet can be measured.

Shuttle run in this study was carried out at a distance of 10-10-10 m. To increase agility, an exercise program is carried out with sub-maximal and super-maximum intensities with stimulation duration between $5-20$ seconds so that the total volume is between $5-15$ times the competition distance. The frequency of stimulation is repeated $5-6$ times per week per exercise, $2-4$ times per week during the competitive phase. Based on some of the explanations above, it can be concluded that the sprint training and shuttle run methods are different training methods in increasing agility. Therefore, the use of the sprint training method and shuttle run have different effects on increasing agility in softball extracurricular participants.

\section{Conclusion}

Based on the results of the research and the results of data analysis that have been carried out, the following conclusions are obtained: 1) There is a difference between the sprint training method and the shuttle run of the base running speed of the softball extracurricular male students; 2) There is a difference between high agility and low agility towards base running speed in softball extracurricular male students; 3) However, there is no interaction 
between sprint training, shuttle run and agility on base running speed in softball extracurricular male students. This research contributes in the field of softball sports, especially in creating an appropriate training program to increase the speed of base running in male students by using sprint training so that results are more effective.

\section{References}

1. ARDIAN, R., S. SUHARJANA \& E. URHAEIN, 2019. Effect of progressive and repetitive part methods against the accuracy of kicking in football extracurricular students. ScienceRise. 1(7), 40-44. https://doi.org/10.15587/2313-8416.2019.174318.

2. BURHAEIN, E., 2017a. Aktivitas Fisik Olahraga untuk Pertumbuhan dan Perkembangan Siswa SD. Indonesian Journal of Primary Education. 1(1), 51-58. https://doi.org/10.17509/ijpe.v1i1.7497.

3. BURHAEIN, E., 2017b. Aktivitas Permainan Tradisional Berbasis Neurosainslearning Sebagai Pendidikan Karakter Bagi Anak Tunalaras. Jurnal SPORTIF?: Jurnal Penelitian Pembelajaran. 3(1), 55. https://doi.org/10.29407/js_unpgri.v3i1.580.

4. Deane, R. S., J. W. Chow, M. D. Tillman \& K. A. Fournier, 2005. Effects of hip flexor training on sprint, shuttle run, and vertical jump performance. Journal of Strength and Conditioning Research. 19(3), 615-621. https://doi.org/10.1519/14974.1.

5. DOSIL, J., J. G. CREMADES \& S. RIVERA, 2014. Psychological skills training and programs. In: Routledge companion to sport and exercise psychology: Global perspectives and fundamental concepts.

6. FRANCOVA, L., H. VALKOVA \& R. SINKOVSKY, 2013. Comparison of training and competition opportunities in leisure time among people with intellectual disabilities in selected European countries. Montenegrin Journal of Sports Science \& Medicine. 2(2), $15-$ 20. Retrieved from http://search.ebscohost.com/login.aspx?direct=true \&db=sph\&AN=90141155\&site=ehostlive.

7. HAKIM, A., R. AMBARDINI, W. NUGROHO \& E. BURHAEIN, 2018. Dragon Fruit Giving Effect Against Malondealdeh?de (MDA) Levels in Muay Tha? Athletes With H?gh Intens?ty Interval Tra?n?ng (HIIT) Method. Journal of Education, Health and Sport. 8(10), 190-198. https://doi.org/10.5281/zenodo.1472727.

8. NIMPHIUS, S., M. R. MCGUIGAN \& R. U. NEWTON, 2010. Relationship between strength, power, speed, and change of direction performance of female softball players. Journal of Strength and Conditioning Research. 24(4), 885-895. https://doi.org/10.1519/JSC.0b013e3181d4d41d. 
9. PARNO, 1992). Olahraga pilihan softball. Jakarta: Kementerian Pendidikan dan Kebudayaan.

10. PHYTANZA, D. T. P. \& E. BURHAEIN, 2019. Aquatic activities as play therapy children autism spectrum disorder. International Journal of Disabilities Sports and Health Sciences. 2(2), 64-71. https://doi.org/10.33438/ijdshs.652086.

11. PHYTANZA, D. T. P., E. BURHAEIN, S. SUKOCO \& S. W. GHAUTAMA, 2018. Life Skill Dimension based on Unified Sports Soccer Program in Physical Education of Intellectual Disability. Yaşam Becerileri Psikoloji Dergisi. 2(4), 199-205. https://doi.org/https://doi.org/10.31461/ybpd.453865.

12. PRAMANTIK, I. A. D. \& E. BURHAEIN, 2019. Disabilities Sports \& Health Science A Floor Time Approach to Improve Learning Outcomes of the Body Roll to the Side in Adaptive Physical Education Learning?: Classroom Action Research Study on Two Cerebral Palsy Students. International Journal of Disabilities Sports and Health Sciences. 2(2), 45-53. https://doi.org/10.33438/ijdshs.652061.

13. PURNOMO, I. D., T, TOMOLIYUS \& E. BURHAEIN, 2019. Development of Learning Activities Playing a Ball on a Goal To Improve Manipulative Skills For Lower Class Students. Proceedings of the 1st International Conference on Science and Technology for an Internet of Things, 2281716. https://doi.org/10.4108/eai.19-10-2018.2281716.

14. SINTARA, K. \& N. SONCHAN, 2015. Physical fitness of collegiate softball players, Burapha University, Thailand. Proceedings of the Burapha University International Conference, (July), 10-12. Retrieved from https://www.researchgate.net/profile/Kawiya_Sintara/publication/280005646_Physical_Fitn ess_of_Collegiate_Softball_Players_Burapha_University_Thailand/links/55a3383008aea81 5dffd389a/Physical-Fitness-of-Collegiate-Softball-Players-Burapha-University-Thailan.

15. SRINIVASAN, S. M., L. S. PESCATELLO \& A. N. BHAT, 2014. Current Perspectives on Physical Activity and Exercise Recommendations for Children and Adolescents With Autism Spectrum Disorders. Physical Therapy. 94(6), 875-889. https://doi.org/10.2522/ptj.20130157.

16. SUGIYONO, S., 2014. Metode penelitian kuantitatif kualitatif dan R\&D. Bandung: Alfabeta.

17. TOOMELA, A., 2010. Quantitative methods in psychology: Inevitable and useless. Frontiers in Psychology. 1(JUL), 1-14. https://doi.org/10.3389/fpsyg.2010.00029.

18. WALLACE, B. J., T. W. KERNOZEK \& E. C. BOTHWELL, 2007. Lower extremity kinematics and kinetics of Division III collegiate baseball and softball players while 
performing a modified pro-agility task. Journal of Sports Medicine and Physical Fitness. 47(4), 377-384.

19. WERNER, S. L., D. G. JONES, J. A. GUIDO \& M. E. BRUNET, 2006. Kinematics and kinetics of elite windmill softball pitching. American Journal of Sports Medicine. 34(4), 597-603. https://doi.org/10.1177/0363546505281796.

20. WIRAT SONCHAN \& A. S. PRATOOM MOUNGMEE, 2017. The Effects of a Circuit Training Program on Muscle Strenght, Agility, Anaerobic Performance and Cardiovascular Endurance. International Journal of Sport and Health Science. 11(4), 176-179. Retrieved from http://www.statista.com/statistics/275056/total-number-of-health-.

21. YOUNG, W. B., B. DAWSON \& G. J. HENRY, 2015. Agility and change-of-direction speed are independent skills: Implications for training for agility in invasion sports. International Journal of Sports Science and Coaching. 10(1), 159-169. https://doi.org/10.1260/1747-9541.10.1.159.

22. YOUNG, W. B., \& B. WILLEY, 2010. Analysis of a reactive agility field test. Journal of Science and Medicine in Sport. 13(3), 376-378. https://doi.org/10.1016/j.jsams.2009.05.006. 